\title{
The impact of information technology on design methods, products and practices
}

Yehuda E. Kalay, Department of Architecture, 382A Wurtser Hall \#1800, University of California at Berkeley, Berkeley, CA 94720-1800, USA

The paper examines the impact of the IT revolution on the design professions, especially that of architecture. It looks at the impacts of past technological revolutions on established methods, products, and practices, and examines the potential impacts of ubiquitous computing, telecommunication, mass-customization and embedded computing on methods of design and construction, and on the products of architecture. This examination leads to conclusions about the implications of these technologies on the nature of architectural practice in the future.

(C) 2005 Elsevier Ltd. All rights reserved.

Keywords: architectural design, built environment, computer aided design, design practice, drawing $(s)$

Corresponding author:

Yehuda E. Kalay kalay@berkeley.edu

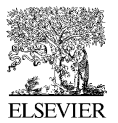

A ssessing the impact of technological revolutions-especially fastpaced ones like those induced by information technology-is difficult, especially when we are still in the midst, if not at the very beginning of the revolution. Nonetheless, or perhaps because we are witnessing only the early effects of information technology on the processes and products of architecture, it is necessary to venture an assessment of accomplishments and an informed view of emerging opportunities in need of further development. To reduce the risk of early obsolescence, this paper only deals with trends, rather than specific products, and only in areas where the new technology promises to have major impacts: the trend towards a more distributed yet integrated process of architectural design; the automation of construction technologies and buildings themselves; and the emergence of an alternative inhabitable space-Cyberspace.

Technological revolutions have been historically closely linked to social evolutions: almost every time society invented new tools, methods, and techniques to manufacture and distribute the products needed for its

www.elsevier.com/locate/destud

0142-694X \$ - see front matter Design Studies 27 (2006) 357-380

doi:10.1016/j.destud.2005.11.001 
survival and growth, these inventions impacted society itself economically, culturally, politically, and in many other ways. Typically, these inventions were incremental refinements of earlier technologies and social structures. But some have had a 'revolutionary' force, causing major economic, political, and social changes. Information technology is such a revolutionary force: it has made the production, manipulation, and dissemination of information cheap and easy. It has made information more readily accessible, hence eminently shareable. It has also made it possible to re-define the traditional sequences of information production and consumption, and re-assign the responsibilities and the privileges of owning it. Consequently, it has had a revolutionary impact on information-centric enterprises, and has been coercing other types of enterprises to adapt information-based practices so they too can benefit from the phenomenal growth potential associated with this technological revolution.

Architectural design is an information-centric enterprise: it analyzes current states of being and devises plans for new states of being that are deemed preferable to the current ones. To do so, it gathers and processes information from many different sources, re-arranges the information, produces new information, simulates its expected impacts and evaluates its desirability. The information it produces is then used by traditional, heretofore information-poor, practices to construct and realize the outcomes of the design phase, which are later used by information-rich habitation practices.

Hence, a technological revolution that impacts information processing has the potential to affect the core processes and products of architecture, and have a 'revolutionary' effect on the profession and the discipline of architecture. It can do so by transforming the current strictly hierarchical design process into a network of design, manufacturing, marketing, and management organizations, where the responsibility for design operations is distributed across multiple professions, organizations, and geographic locations. It can do so by transforming the access to the information from a sequential process into an interleaved one, where decisions are made in an a-synchronous yet coordinated manner. It can accentuate and promote the configurational principles underlying architecture (the integration of disparate standardized products and services into a unique whole), thereby promoting mass-customization and lowering costs without sacrificing quality.

Furthermore, by embedding inter-connected computational devices in both the building components themselves and the means of assembling 
them, the process of construction and its products can become more 'intelligent,' able to respond to the changing needs of the occupants without re-design, thereby affecting what can and needs to be designed in the first place.

Finally, the advent of the Cyberspace-an alternative 'space' in which more and more activities 'take place' (learning, shopping, entertaining, transacting business, etc.) - can promote a new kind of 'architecture,' in its most cherished sense of place-making, though dressed in a different physical cloth - a virtual architecture unburdened by the laws of nature yet nonetheless capable of sustaining social, cultural, and economic activities.

Some of these changes are already evident today, albeit in a rather primitive, tentative, even bungled form. Most applications of computational technologies in architecture are still in their 'horseless carriage' phaseemulating older techniques and methods, like computer-aided drafting and modeling. Yet, in spite of its early, humble manifestations, information technology promises to become a revolutionary, rather than evolutionary development in the history of architecture. Like other revolutions, it will take time to explore, develop, and accept the new possibilities. Their effects will likely be felt by the professionals who have traditionally been entrusted to design and construct the buildings, and by the society that uses them.

\section{Interleaved, collaborative design}

Architectural design and the construction of buildings have always been collaborative efforts, involving many individuals representing many different skills. Managing collaboration to produce desired results is a highly complex and challenging task. It becomes even more difficult when the participants are highly skilled and highly educated professionals, representing different fields of expertise. This is the case in $\mathrm{A} / \mathrm{E} / \mathrm{C}$ (Architecture, Engineering, Construction), which involves individuals representing often fundamentally different disciplines who, perforce, hold different goals, objectives, and even belief systems. Furthermore, these professionals often belong to independent organizations who temporarily join forces to accomplish a specific project. While they work together to achieve the common, short-term goals of the project, each participant and organization also has its own long-term goals, which might be in conflict with some of the goals of the joint project (including financial, legal, ethical, professional, and other goals), thereby introducing issues that are extraneous to the domain of collaboration. Lastly, although their participation in the project may be short-termed compared 
to lifetime of the project itself, the effects of their collaboration, in terms of the decisions they made and the action they have taken when they were part of the project team, may well impact and constrain the freedom of action of other participants long after the original participants have departed.

\subsection{Methods of collaboration}

Professional practices in $\mathrm{A} / \mathrm{E} / \mathrm{C}$ have long recognized the need for collaboration, as evidenced by the ancient Biblical story of the Tower of Babel. They have generally adopted one of two methods to address it: hierarchical decision making and temporally partitioned responsibilities.

Hierarchical decision making among the professionals comprising an $\mathrm{A} /$ $\mathrm{E} / \mathrm{C}$ design team takes the form of contractual arrangements, where one of the participants (often the architect) is appointed team-leader, and the rest are considered sub-contractors or consultants. While this arrangement may be efficient in terms of process (i.e., getting the job done), it introduces the risk of diminishing the overall performance of the product by reducing the commitment of the sub-contractors due to their diminished ownership or influence on the product. The overall result, therefore, is often less than optimal.

Temporally-partitioned responsibilities represent the typical 'over the wall' practice of transferring responsibility for the project from one design professional to the next as it moves along the design/build/use process. Thus, the responsibilities of the architect end when construction begins, and the construction manager's responsibilities end when the facilities manager or the owner takes over. While this method is efficient in terms of process, and has the added benefit of compartmentalizing legal and other responsibilities, it is detrimental in terms of quality: the carefully considered knowledge which has been developed and applied in earlier design phases is lost when the responsibilities are transferred. Moreover, knowledge that resides in 'downstream' participants is not available to the 'upstream' participants (e.g., the availability of better methods or products than those specified by the 'upstream' participant, or the unavailability or incompatibility of those specified).

\subsection{Interleaving}

Computational methods aimed at facilitating collaboration have focused primarily on assisting the communicative aspects of collaboration in $\mathrm{A} / \mathrm{E} / \mathrm{C}$. These have resulted, on one hand, in Building Information Models (BIM) that, in addition to the product's geometry, also stores many of its other attributes and can convey much more information 
than traditional drawings and models can. On the other hand, they have resulted in computational systems that can facilitate the management of the design and construction processes by tracking drawings, managing their different versions, and coordinating concurrent access to the information.

The thesis of this paper is, however, that these incremental improvements are much too limited in their scope, and fail to capitalize on the revolutionary aspects of the information technology. Moreover, they solve the wrong problem, namely-controlled data management: the organized transfer of information among the participants, subject to centralized control. This approach may enhance the efficiency of the process, but it does so at the expense of the quality of its products: it virtually enshrines the "symmetry of ignorance"- the inability of one professional to understand the needs and responsibilities of other professionals - thereby guaranteeing that the integrated composition of the individual solutions, each of which may have been optimized for its own purposes, will not overall be optimal. The benefits and drawbacks of this approach have been clearly demonstrated by lean production techniques used in the automotive and other industries, where they helped streamline existing processes but failed to improve the products themselves or to stimulate the invention of new products (Womack et al., 1991).

Rather, this paper contends that the key to understanding the link between technological innovations and the design, construction, and use of buildings is to understand the building procurement process as a whole integrative process, where changes in one component affectand are affected by-others. Thus, rather than consider the process as largely sequential, consider it an interleaved process.

Unlike pre-arranged hierarchical or temporal partitioning of the process, interleaving is a flexible way of interconnecting different participants for design or business purposes (Aberdeen Group, 1999). It has ramifications for how design and procurement are done, hence for what can be done. By exchanging information as problems arise and as solutions are developed, it is possible not only to assemble a design-build-use team that can support innovative design ideas, but also to conceive such ideas in the first place: it is likely that one (or more) of the participants have capabilities that will allow others to come up with design or procurement solutions they are unlikely to conceive on their own. 
Interleaving is not dependent on information technology, as evidenced by famous collaborations such as between Watson and Crick, Rogers and Hammerstein, Bardeen, Brattain, and Shockley (the inventors of the transistor), and others. Yet, as a method, it has been largely impractical without the help of information technology. The speed and access offered by information technology can shrink the lag between the conception of an idea by one participant and its communication to other participants for the purpose of review, comment, or as a springboard for new ideas. Thus, although information technology is merely a technical, quantitative measure, it has qualitative implications as well: it can support, or at least accommodate, the uniqueness and unpredictability of creative design processes (as well as other network-based organizational relationships).

The principle guiding this approach is viewing information as a distributed, freely-accessible commodity. The underlying technology comprises high-speed, reliable, secure communication, browser-based standardized user-interfaces, object-oriented product descriptions, URL-style location transparency, secure business tools for bidding, billing, and servicing (updating) products, and business models that are more flexible than traditional contracts. Utilization of such tools substitutes accessibility for the transfer of information: the information resides at its owner's location, from where all authorized participants can view it, rather than shipped to the user's location. It also distributes ownership and responsibility for conforming to each other's needs and to the overall needs of the project among the participants, binding them in appropriate contractual relationships (e.g., who may update what parts of the information) instead of 'work for hire' relationships. The 'controller' is replaced by a facilitator, a coordinator, or a 'configurator', whose responsibility is to make sure that individual contributions are made on time and that the overall process progresses towards meeting its goals. Decisions concerning the overall direction of the project may still be made by one of the participants (e.g., the client or his/her representatives), but they are transmitted to the affected parties as constraints on their individual contributions rather than as instruction to be fulfilled.

Interleaving is a familiar concept to jazz musicians, who improvise their musical contribution in concert with those of other members of their band. In larger musical settings, the conductor of a symphonic orchestra can be considered a 'configurator', who directs each player to play her part on time and according to an overall schema. Yet each player is responsible for her own part of the music, often notated in a form that is different from that used by other instruments. 
Such a collaborative procurement model was pioneered by Wal-Mart Stores - the world's largest retailer of general merchandise goods-and was quickly emulated by its competitors. Instead of automating order processing between its stores and its suppliers, Wal-Mart's Efficient Consumer Response (ECR) Initiative uses an eChannel supply demand/product, called MyVision, to collect data at the checkout counter from each transaction, compare it to inventory levels, and-when inventories fall bellow a prescribed level-notify the respective supplier. It is then the supplier's responsibility to re-stock the indicated store with its products. Thus, Wal-Mart always has the right level of inventory for each product in each store, without assuming the responsibility for producing, inventorying, or even delivering the products, all of which it has successfully transferred to the suppliers. The overall result is minimizing the total cost of the retail supply chain.

Perhaps the best example of the efficacy of this method in the $\mathrm{A} / \mathrm{E} / \mathrm{C}$ industry is Frank O. Gehry \& Associates, way of approaching the design and construction of complex building forms. The practice is known for its innovative, sometimes controversial buildings, like the Guggenheim Museum in Bilbao, Spain (1997), the Disney Concert Hall in Los Angeles, California (1989-2003), and the Experience Music Project in Seattle, Washington (1999-2000). It can be argued that without using an interleaved approach, based on a shareable building model from where the structural engineer, the steel fabricators, the cladding manufacturer, and the other participants derive the information they need for their own actions, it would have been impossible for Gehry to design his unique buildings in the first place (or rather, they would have remained paper-projects, which could not be realized for technical and/or economical reasons).

\subsection{Consequences for collaboration in the $A / E / C$ industry}

It is not at all clear at this time that architectural design processes in general are amenable to similar techno-organizational changes, nor how exactly will information technology enabled design environments look. They are likely to be structured around a high-bandwidth communication network, which will link location-transparent, distributed data sets, each representing the individual contribution of one participant. The data formats need not-indeed cannot-be the same, for each discipline has developed its own tools and representations that are most appropriate for its domain. Nonetheless, these data sets will be tagged through XML or similar cross-platform standards, so critical attributes can be recognized across disciplines. If Collaborative Product Commerce 
(CPC) methods such as those used by Wal-Mart and by Gehry are indicative of a trend, then the participants will be organized as a network of service and product suppliers, who will offer alternative solutions for their part of the collaborative project, subject to goals and constraints established by other participants. These solutions will be reviewed by the respective participants for conformance to the overall needs of the project, and for their impact on each participant's own domain of expertise. The process will not be completely linear, as it is now, nor will it be parallel, because the solutions provided by one participant serve as input, or at least as guidelines, to others. The envisioned process will be fluid, dynamically negotiated, and mutually stimulated, providing the participants with a greater stake in the results, and therefore a greater commitment to its success.

The most important impacts of a network-based collaborative approach on architectural design will be its transformation from a hierarchical linear process into a distributed, interleaved process, where the sequence of inputs is not pre-determined, but rather opportunistic. It means that opportunities can be recognized and acted upon in time to make the most of them, and problems can be spotted earlier, when they arise, because more specialists will have access to the evolving product: they will not have to wait their turn to be consulted, at which time it may be too late to recognize an opportunity or to avoid a problem. The avoidance of problems will lead to reduced design time, and greater satisfaction of all parties involved.

The roles of the individual participants stand to change as well, much like they have changed during the 15th century when the profession of architecture adopted scale drawings as a means of communication, and in the 18th century when factory-based production supplanted the cottage industry. The traditional role of the architect as the lead player in the design process may diminish, while the respective roles of other specialists-like consultants and suppliers-may increase. Although the administrative roles of the architect may erode, his/her contribution will not: design will still need the overall creative vision provided by architects, which is different from solving technical problems associated with its realization. On the other hand, the contributions of other participants in the design process will shift from 'problem solvers' to 'contributors', increasing their commitment to the project.

Overall, the hierarchical structure of the process - and the organizations who are engaged in it-may 'flatten out', changing from 'command and control' to 'coordination and communication'-a structure Robert 
Reich (Secretary of Labor in the Clinton administration) calls "collective entrepreneurship" (Reich, 1987). It makes the process less bureaucratic and more able to respond to opportunities and to changing needs (which are inevitable in design processes).

Such a transformation depends on, and is shaped by information technology, which provides a means of communication among the specialists, as well as helps them individually gain access to knowledge- and databases. However, it is not a simple addition of information technology to an existing process and organizational method. Rather, it is a combined techno-organizational change, where the respective roles and links among the participants change along with the technology (Benne, 2004).

\section{Building automation}

It may seem that the automation of construction processes and of the buildings themselves has little to do with the process of design: after all, by the time construction begins, and even more so-once the building is completed - the process of design is long done. While it is true that the design phase precedes the construction or use of the building, it is the latter two phases that inform the design phase what it can and ought to do, as much as the design phase informs the other two phases of the building's lifecycle.

Examples of how construction technologies impact the design of buildings are abundant in history: the adaptation of the Etruscan keystone arch enabled Roman engineers to build extremely strong and durable bridges, and led to the invention of the dome as early as 27 BC. The invention of the Flying Buttress, which receives the gravitational thrust of the roof, allowed Middle Ages, Master Builders to develop the Gothic Cathedral, replacing the Romanesque's massive walls and columns by relatively thin and tall walls and soaring vaulted ceilings. Since the walls were relieved of much of the burden of the roof, they could accommodate large stained glass windows, which transformed the interior of the church from a dark and confined space into a light-filled spacious cathedral. Henry Bessemer's invention of mass produced steel in 1855, coupled with Elisha G. Otis' invention of the safety elevator in 1853 and Werner von Siemens, invention of the electric elevator in 1880, allowed the design and construction of skyscrapers, such as Daniel Burnham's 285 feet tall Flatiron building in New York (1902).

Thus, technological innovations-often several of them coming together at the same time-have always had a significant impact on the design of 
buildings. The advent of computer-assisted construction technologies, and of computer-controlled buildings, promises to have as much of an impact on the architectural design process and its products as these earlier technological advances have had. On the construction side, computing facilitates a much tighter and better-controlled information transfer between the design team and the builders, permitting the design of more complex structures that could not have been built at all, or would have cost too much to build without computational assistance. On the building operation side, computing allows for finer control of the built environment, making it possible to design dynamically-stabilized structures that are lighter, taller, and more economical than statically stabilized structures, both structurally and environmentally. Computing also makes the control of the interior environment more responsive to changing needs, such as different light levels during the day and different heating and cooling needs over the year. By making them more efficient, computers allow architects to design building that clients would have balked at due to maintenance and lifecycle costs.

\subsection{Construction automation}

The Experience Music Project (EMP)—designed by Frank O. Gehry \& Associates-illustrates, among other things, the relevance of construction automation to an architect's ability to design and build unique buildings. It was commissioned by Paul Allen, one of Microsoft Corp. co-founders and an avid fan of guitarist Jimi Hendrix (1942-1970), who was known for smashing guitars as much as for his music. The inspiration for the 140,000-square-foot interactive music museum, celebrating creativity and innovation as expressed through Rock'N'Roll and other forms of American popular music, came from Hendrix' own music and from electric guitars, their shapes, colors and strings. This exuberance of form renders the EMP different from all other structures, and required a different approach to its design and construction.

Most curvilinear structures-including others by Frank Gehry-use flat planes that have been bent in just one direction, or are based on curves that are symmetrical in some aspect. The EMP, on the other hand, is totally freeform: it is nonsymmetrical and curves at every point in many directions at once.

Gehry shaped the building using cardboard, tin foil, and wood. These physical models were digitized into CATIA, a 3D modeling software developed by Dassault Systems in France (marketed and supported worldwide by IBM). The resulting 3D database, whose development took over three months, formed the core of the design and fabrication 
process. It enabled Gehry and his design team to accurately model and test the shapes chosen for the building, and to optimize the surface curvatures such that they maintain the desired form but have better buckling capacity then some of Gehry's original shapes did.

Supporting the complex form was not amenable to standard structural solutions. Instead, Skilling Ward Magnusson Barkshire-the structural engineers for EMP-developed a steel structure that stiffens the concrete shell of the building by adapting bridge construction technologies, which produced a ribcage-like structure comprising 240 ribs. Each of these ribs were created by welding three steel plates together to form an I-shaped member. Each plate was cut by computer-controlled torches, deriving its data directly from the 3D model, and molded into the required shape by means of computer-controlled rollers.

The steel and aluminum shell that clads the building was adapted from automotive technologies. It comprises 3000 steel and aluminum plates, each made of 7 uniquely shaped and cut shingles. In addition to the cladding, the building is 'draped' by 621 pieces of $3 / 4$ inches laminated glass, representing broken guitar strings. These were manufactured by the Italian Permasteelisa Cladding Technologies company, using the same 3D project database that was used for the structure and the skin. Each pre-fabricated glass component, weighing in excess of 200 pounds, was installed from a tower crane, and was positioned using laser-guided surveying instrumentation.

\subsection{Smart building materials}

The impact of information technology on the product of architectural design - the building itself - will manifest itself through enhanced 'intelligence' of the materials from which buildings are made, and facilitating their responsiveness and adaptability to changing needs.

The properties of the materials from which buildings are made have always been an inseparable part of the process of architectural design: pozzolana cement allowed the Romans to build their baths, the Coliseum and Pantheon in Rome. Iron (and later steel) reinforced concrete, invented in 19th century, allowed the design of longer span bridges and taller buildings. And the industrialization of plate glass production made possible the 'glass box' International Style architecture of the first half of the 20th century.

It was not, however, until the second half of the 20th century that 'smart materials'-ones that can adapt themselves to the changing needs of the 
occupants or the environment-have emerged. Unlike traditional materials, such as wood, stone, steel, and glass - whose properties determine what the building looks like and how it behaves once and for all-smart materials can be engineered to fit the needs of the building even when they change over time. This, in turn, determines not only how buildings are designed, but also what can be designed: instead of designing the building for a finite state, designers who use smart materials can design their buildings for a sequence of behaviors. For example, the eight-story NASDAQ MarketSite Tower at 4 Times Square in New York City is wrapped in an 10,800 square foot cylindrical media wall, which is made of more than 18 million LEDs embedded in black rubber-based compound. They comprise eight display screens that operate simultaneously, driven by one video processor each and an array of 800 digital switching power supplies. This $\$ 37$ million electronic billboard, developed by Saco SmartVision of White Plans, NY, operates like a curved television screen with $170^{\circ}$ viewing angle: it transforms the building into a 'live' entertainment and advertising center for thousands of Times Square daily (and nightly) visitors.

While the media wall of the NASDAQ building may not qualify strictly as a 'smart material', it does conform to the general definition of such materials as ones that can change their shape or other characteristics in response to some externally-applied stimulus. The change may involve the material's shape, transmissivity, viscosity, or luminescence, as is the case with media wall. The input stimulus can be electrical, mechanical, thermal, chemical, or radiation. The effect occurs at the material's molecular level, where it can either change the properties of the material itself, or convert the input energy from one form into another (in the case of the NASDAQ media wall, from electrical stimulus to light output). For smart materials, these changes are reversible: when the input stimulus is removed, the material reverts back to its original properties.

Some materials respond by converting the external stimulus into strain, which elongates the material; or conversely-produce electrical output when mechanical strain is applied to them. Such materials can be used as sensors and actuators, and have found use in detecting stress in walls and foundations, even stiffening them as a response to earthquakes or wind conditions. Such actuation or sensing are, of course, picked up and directed by computers that regulate the building's response according to some pre-determined program. 


\subsection{Intelligent buildings}

The significance of smart materials for the design phase of buildings comes from changing the building (or its surfaces) from a static entity into a dynamic one: it can be made an active participant in the environment in which it is embedded, rather than a backdrop 'prop' for other actors' activities. The responsiveness of buildings to their environments is not limited to their surfaces: other building systems can be made responsive, or automated.

Enabling the building to sense and respond to changing needs takes many forms. The simplest application is based directly on the feedback loop, where some action occurs in response to an external stimulus. That is how thermostats turn HVAC equipment on/off based on sensing the current temperature and comparing it to the pre-set temperature; automatic doors open when their sensors inform them that a person approaches; external sun shading devises can be controlled by means of sensors that respond to direct sun-light; lights can be turned on/off as required by the presence of people and the level of outside illumination; and security systems can respond to the presence of intruders by sensing motion. Feed-back based adaptability is a relatively simple approach to automation, which has been around since WW II, and reached a state of maturity as evidenced by the proliferation of commercial products and companies that support them. The role of computers in this kind of automation is mostly to control and coordinate the various systems, and keep a $\log$ of their operation.

Adding a functional model of the environment to networked building systems and appliances allows for a more far-reaching responsiveness and adaptability: it helps to regulate the environment in expectation of events, rather than in response to them. A functional model of a building is one where behavior patterns are programmed in advance, based on learning the typical behavioral preferences of the occupants, so the building environment can anticipate and position itself to support recurring events, not only to respond to them. For example, elevator schedules can be automatically adjusted by the system to meet peak demand in the morning by stationing empty cars close to the building's entrance. In the afternoon, when the traffic is reversed, the empty cars can be stationed at the top floors of the building, thus saving the trip time an empty elevator must make to reach those floors from its station at the bottom of the shaft. Similarly, a house equipped with such a model-based adaptability system could optimize household operations, for example by turning on the water heater an hour before the washer is scheduled to 
be used, thus conserving energy yet ensuring there is plenty of hot water available by the time it is needed.

An example of a habitable environment equipped with model-based adaptability has been demonstrated by MIT's Intelligent Room project (Coen, 1998), which was intended to integrate computers seamlessly in ordinary environments so they could take care of mundane, everyday activities. The interaction with these computing systems was done by voice, gesture, and context, rather than through keyboards and mice. As such, the Intelligent Room was equipped with sensors (video cameras, microphones), connected to image understanding and speech recognition systems, which enabled it to 'know' where people are in the room, and what they are doing. The system could not only perceive, but also interact: it could talk back and perform actions on behalf of the inhabitants (even when not explicitly told to do so). For example, upon entering the room, the visitor might have been recognized as the habitual occupant of the room, and greeted by name. The room would then proceed to tell the office owner of the messages awaiting to be answered, contact people as required (or schedule a mutually convenient meeting time with their own intelligent offices).

What made MIT's Intelligent Room possible was the advent of computer vision and speech recognition systems, and the ubiquity of cheap yet powerful computers. The major hurdle has been, and largely remains today, the integration of many independent systems into one composite, interoperable system, in which each component supports and enhances the others. For example, identifying the combination of speech and gesture-a common human action-requires identifying the speaker from among several people in a room, the fact that $\mathrm{s} / \mathrm{he}$ is pointing at something, and the direction of that gesture. The context, which is necessary to interpret both speech and gesture, is provided through the modelbased adaptive environment, in the form of pre-defined scenarios.

Model-based adaptability, which can anticipate necessary actions, still falls far short of the scenario described in the early 1970s by Nicholas Negroponte in his influential book Soft Architecture Machines. Negroponte proposed that an intelligent, self-cognizant environment could replace all the professional functions of the architect, and better serve the occupants. He questioned whether architects were unnecessary, perhaps even detrimental, middlemen between the clients and the fulfillment of their needs, agents who dictate the decisions made by their clients in matters the clients know better (Negroponte, 1975). Instead, he proposed that the environment itself will be made responsive to the 
ever-changing needs of its inhabitants. It will not only 'help' humans design their habitat, but rather 'be' the habitat itself.

Such total environmental adaptability is no longer a matter of science fiction nor speculation: it has been demonstrated by the University of Colorado's ACHE (Adaptive Control of Home Environments) project (Mozer, 1988). In a house that was specifically equipped for the purposes of this project (by running five miles of low-voltage cables), researchers explicitly avoided using sophisticated user interfaces. Instead, the environment itself monitors how the inhabitants use ordinary appliances, and apply those observations-in combination with sensors that monitor the state of the house's environment-as training indicators of the inhabitants' preferences. As the house becomes better 'trained', it can anticipate the users' preferences and adjust the operation of devices accordingly, gradually freeing the inhabitants from the chores of manually controlling their environment. For example, the 'house' can automatically maintain the preferred room temperature given the preferences of particular occupants, their activities, and the time of year. It can choose different patterns of lighting for different activities, and schedule the heating of water for anticipated bath or washing clothes. The house's operations are transparent to the inhabitants, other than the fact that they do not have to worry about managing the various devices in the home. The house, in effect, has become an intelligent agent that infers the inhabitants' desires from their actions and behavior.

The consequences of these progressively more responsive buildings for the design process will be profound: much like smart materials transform the building from a passive object into an active participant in its environment, building automation techniques will transform it from a passive container into a responsive 'partner' in the process of inhabitation. The architect's role will be transformed from designing an object to choreographing the responses of a 'living' machine. The transformation has technical, economic, social, even legal effects (whose fault will it be if the intelligent house fails to summon help when an elderly inhabitant falls down and cannot get up to reach the phone herself?).

\section{Virtual places}

Architecture, above everything else, is the art of making places: environments that support and enhance human activities such as living, learning, working, socializing, and transacting business. The places that the architects develop differ from mere 'spaces' in that they embody social and cultural values, in addition to spatial configurations. It is the concept of 'place', not space, that connects a building to its context, and 
makes it responsive to given needs. While places are made of objects and spaces, they also involve inhabitation: the people who use them imbue spaces with social and cultural meaning, thereby transforming mere 'spaces' into 'places'. In turn, places frame human actions by providing cues that organize social behavior: people rarely sing or dance when they present conference papers, although conference halls and a theatres share many similar spatial features (lighting, orientation, etc.). Conversely, the same space-with no changes to its layout-may function as a theatre at a different time, when the presentation of a scholarly paper would be considered 'out of place' (but not 'out of space') (Harrison and Dourish, 1996).

The advent of computers and computer-based telecommunication has now opened up new opportunities for architects to make places that did not exist in the past: the opportunity to inhabit a different kind of space-the Information space. Cyberspace, as the information space has been dubbed by William Gibson in his 1984 novel Neuromancer (Ace Books, New York), has become accessible in the 1990s through the World Wide Web. Cyberspace has quickly become much more than just another means of communication: it has become a destination all of itself. People shop 'there', are entertained 'there', and get educated 'there'. To paraphrase Gertrude Stein, "There is a There There", even though it can only be experienced through the mediation of computers. Cyberspace is thus quickly becoming an alternative 'place' where everyday economic, cultural, educational, and other human activities 'take place'.

With few exceptions, Cyberspace designers have not yet begun to capitalize on the theories, experiences, and practices that have been guiding architects in physical place-making. Rather, they adopted the document metaphor, which has guided computer-human interface design since it was invented by Xerox PARC ('the document company') in 1975. But, as the Web matures, and as it assumes more fully its role as a space rather than as means of communication, there is a growing need and opportunity to design it according to architectural place-making principles: spatial settings that not only afford social interaction, but, like physical places, also embody and express cultural values. At the same time, because Cyberspace lacks materiality, is free from physical constraints, and because it can only be inhabited by proxy, these 'places' need not resemble their physical counterparts. 


\subsection{Making places}

Places are the product of human intervention: they have to be created, through practice and appropriation, and made to fit into the culture of society. Place-making is the conscious process of arranging or appropriating objects and spaces to create an environment that supports desired activities, while conveying the social and cultural conceptions of the actors and their wider communities (Canter, 1977).

Place-making is a process of creating conditions that afford and encourage the emergence of a particular sense of place. In the physical world places are often designed by borrowing function, form, and conception from precedents, symbols, and metaphors. This 'whole-sale' approach is based on the assumption that a combination that proved to be appropriate in earlier circumstances will, with proper adjustment for the new context, continue to be so again for the same activity/conception. Researchers call this approach designing from Patterns, Case-Based Design, or more recently, Object-Oriented design: the instantiation or judicious adaptation of a 'source' template, archetype, or precedent to fit the specific needs and circumstances of a 'target' context.

If no appropriate precedent can be found, symbols and metaphors may be used to engender some inherent quality embedded in the 'original'. In this case, the fit may be more tenuous and require some explanation. Alternatively, altogether new forms may be developed that, if found to be functionally and conceptually 'appropriate', may acquire their own status as precedents (e.g., Frank O. Gehry's curvilinear forms). Although the intent of both adaptation and invention is to give form to the designed place, they also confer on it certain conceptions that are associated with the metaphorical sources (e.g., power of the court as a 'temple' of justice, etc.).

It is easy to understand, therefore, why Cyberspace has, to a large extent, been given the form of 'pages': the two main metaphors of the Web-as the 'mother of all publishing houses' and as mail-order retail (or e-tail) outlet-have been shaped by the forms and conceptions that worked so well, for so long, in physical space. They were borrowed from scholarly papers and from product catalogs, which proved so successful in selling mail-order goods for Montgomery Ward, Sears Roebuck, JC Penny, as well as countless other retailers. A similar logic guided Cyber-worlds that purport to support 'meetings', and have, therefore, borrowed the metaphor of a physical conference room. 
The shortcoming of the 'borrowing' approach, and the most common cause for its failure, is of course assuring that the 'source' and the 'target' are similar enough to justify using similar formal solutions and conceptions. Hence, one must question whether Cyberspace is similar enough to physical space to justify 'borrowing' forms and conceptions, even functions, which were developed explicitly for the 'real' world: after all, it has no gravity, and no sense of orientation. There is no real notion of up and down when 'riding' an elevator; visitors to an office or conference room cannot sit on 'chairs' or put their notes on a table. Hence, the spatial metaphor may actually be of much less value in facilitating interaction and engagement than it has been in the physical world.

With the advent of VRML, spatial models are becoming increasingly more popular in the design of Web environments. These designs are based on the assumption that, since many aspects of our social and cultural behaviors are organized around spatial elements of the physical world, we can carry over these patterns of behavior to virtual environments by designing them to have the same affordances for interaction and meaning that the physical world exhibit.

While this hypothesis seems plausible, current implementations do not yet exhibit the sense of environmental quality or socio-cultural significance that could confirm it. Therefore, it is not yet possible to gauge the effect of Cyber-'placeness' on the economic, educational, or cultural activities for which the Web is used.

\subsection{Virtual places}

So what can be gained by adopting place-making principles for the design of Cyberspace? What are the inherent advantage of Cyber-places, vs. Cyber-spaces?

In the physical world, the advantage of culturally and environmentally rich places-like San Francisco, Venice, and Paris-over mundane, culturally and environmentally poor places like suburban Detroit or Philadelphia, is obvious: excluding economic constraints, most people will prefer to spend their limited leisure time in the former, rather than the latter ones. While both types of environments can provide similar levels of service, the environmental, social, and cultural richness-and the sense of place they engender-play a key role in determining their appeal.

The advent of virtual places can be traced to the video gaming industry. The initial constraints of the technology led to the design and marketing 
of games with visually crude graphics and simple $2 \mathrm{D}$ environments, like Pac Man and Tetris. But the improving technology allowed for designing games like Myst and Riven, which revolutionized the industry. They created a clear sense of place at both the larger 'world' scale, and the room scale. These environments are familiar, yet futuristic and unique, which makes the games intensely attractive. While the mystery/puzzle plot of the game is important, it would hardly come off without the rich place-based environments that serve as its context. They are able to create places people actually want to be in, rather than the environmentally-shallow 'dungeon' games, where the crude nature of the context hindered, rather than enhanced, the game (as evidenced by the phenomenal growth in the video game industry that took advantage of the advancing technological capabilities).

It is logical to assume that designing places in Cyberspace can, indeed must be, informed by the principles that have been guiding physical place-making for centuries, for the sake of environmental, social, and cultural richness. This transformation, however, is not a matter of simply emulating physical form in electronic environments: Cyberspace cannot be 'specialized' by appropriating physically-based metaphors: objects and spaces that were functionally and perceptually 'appropriate' in the physical world lose their appropriateness in Cyberspace. On the other hand, having been conditioned from birth to function and perceive the physical world, we carry the expectations and sense of 'appropriateness' to Cyberspace. For example, while it is unnecessary to use a table to support objects in Cyberspace, we sense a rather uncomfortable feeling when objects simply 'float' in Cyberspace. And while the lack of gravity permits us to walk on the walls or on the ceiling (if they exist at all), the impression such freedom produces is quite surreal (as has been so aptly illustrated by the Dutch artist M.C. Escher).

On the other hand, the digital realm offers place-making opportunities that do not exist in physical space: distances lose their meaning (they can be traversed in an instant), as do spatial boundaries. Even time can be easily manipulated (we can visit cities that no longer exist, or do not yet exist). Choosing the right balance to engender the desired sense of place, without falling into the traps of indiscriminate 'borrowing' from physical space nor discarding everything we learned from it, is the challenge facing Cyber place-making. 


\section{A square peg in a round hole or a horseless carriage?}

Technologies are not planned: they emerge as culture evolves. Perhaps that is why their effect on established practices is rarely guided by reflection. More often, as traditional tools are transformed by new technology, it is the practices themselves that must adapt to the changing context. Gradually, the effect of these adaptations becomes known, but by then the practices have been irreversibly changed, often with unintended consequences: even their purposes and values may be displaced by the qualities and capabilities afforded by the new technologies.

It is the intent of design technology to help architects work more intelligently, more responsibly, more efficiently, more effectively, and more carefully. Representational methods and tools, for example, which comprise a large part of this technology, are employed to assist architects in reasoning about and communicating the acts required in designing. But the representational technology that is used to help architects explore abstract designs ideas is not neutral: it interposes itself between the idea and its presentation by appropriating our "logistics of perception": it blurs the distinction between the designer's intent, and what has been accomplished through the technological means used to express that intent (Virilio, 1984). As the mediator, technology serves not only to communicate some knowledge, but also to determine what is knowable.

One measure of the influence technology has on the task it is employed to assist is its affordance: the potential of the technology to enable the assertive will of its user (Gibson, 1977). For example, designs derived from working primarily in scale drawings can result in an architecture that is less expressive three-dimensionally than that which results from working with massing models (Halasz, 1979). Scale drawings and physical models have certain potentials that emphasize different qualities of the idea at the expense of others. Because the affordance of the tool in-

fluences, channels, and even directs the reasoning that goes on during the design process, it must be chosen carefully to match the task at hand.

The introduction of computing technologies into the design process and its products provides new affordances. The efficiency, control, and intelligence afforded by these tools have become increasingly essential to architectural practices. CAD tools make the production of contract documents more efficient and better coordinated. In a similar fashion, computer modeling has reduced the production costs associated with making physical models while increasing the options for their end use. 
The ubiquitous proliferation of telecommunication networks has made it possible to involve more experts, more frequently, in the design process. The availability of microprocessors and control systems has made it possible to defer what were early design decisions to latter phases of the design, construction, even use of buildings. And the advent of Cyberspace has opened vast new opportunities for designers to apply their knowledge of placemaking in a new domains. But while it is clear what needs have dominated the development and adoption of computational tools in the profession of architecture, it is less obvious how, increasingly, this technology is influencing its practice beyond the fulfillment of those needs. In many cases, the influence is misunderstood or goes undetected at all. As designers embrace the new technology for all its benefits, they must also become increasingly more cognizant of its less obvious impacts on their work and its products.

In this regard, the uneasy relationship between novel computational principles, methods, and tools, on one hand, and the ancient discipline of architecture, on the other, can be interpreted according to two different paradigms. The first is that of forcing a square peg into a round holeimplying that the use of the new tool is misdirected, or at least poorly fits the processes that have traditionally been part of architectural design. The second paradigm describes a state of transformation, where the new technology is viewed through the lens of the practice in obsolete and 'backward' terms, much like the automobile that was viewed as a horseless carriage in the early days of the 20th century. It implies a lack of appreciation for the emerging potentials of technology to change the task to which it is applied (Chastain et al., 2002).

The 'square peg in a round hole' paradigm describes tool making as a problem of adapting a new technology to current practices. As a new technology is introduced into practice, a dysfunctional relationship can develop between the tools and a task, either because the task is poorly understood or because the process of displacing a traditional technology is largely one of the substitution of habitual tools with new ones that have the wrong affordances. Such inappropriate use of the technology results in a poorer practice. For example, using precise drafting tools such as AutoCAD ${ }^{\circledR}$ early in the design process-where ambiguity and flexibility are needed more than preciseness-requires the designer to decide issues whose time has not yet come, thus interfering with the evolution of design ideas. Moreover, it can mislead the viewer of the design (including the architect him/herself) to read more precision in the design than it deserves. Understanding this paradigm (and resolving the dysfunction it brings in its wake) requires a clear 
identification of the different actions that comprise the design process, and developing computational tools that can truly assist them-what amounts to 'rounding off' the square peg.

The 'horseless carriage' paradigm views technology as a means to alter the perception of a practice about itself, as it is transformed by a new technology. In using the term a 'horseless carriage' at the turn of the 20th century, the task of transportation has been described through the lens of a previous technology, not realizing that the practice of travel had dramatically changed. Understanding this paradigm requires asking a different question than the first one: rather than how can the new tools assist designers, one should ask how do the affordances they provide change the practice of design itself? Do we understand how having more precision early in the process affects our reasoning about design options? Do we understand how communication via digital files and video screens fundamentally changes the culture of the practice? How does knowledge, once invested only in the designer but now ingrained in the tools, even in the products themselves, affect the practice of design? This paradigm, like the first one, assumes that the fundamental task does not change (i.e. the task of designing of a habitable environment). But unlike the first paradigm, it assumes that the practice of design is not only assisted, but is changed through the influence of the new technologies.

In both paradigms, the tools are connected to an image of practice (Boulding, 1956). This image is a description of methods, habits, organization, knowledge, and culture of design in relationship to a task. Architects often hold such an image of their practice, but not always explicitly. They may know how something is done, but are less aware of the values implicit in a particular way of working.

Computing has had only a few decades of experience with the practice of architecture, as compared to other technologies' (predominantly, drawings) long history. Therefore, it is not surprising that the fit between the affordances offered by computing technology and design practice is more problematic than those faced by earlier technologies. The question is how to understand those affordances and evaluate their impact on the profession and practice of architecture.

The first paradigm offers one approach—smoothing off the square peg. This begins by observing what designers do. This is an empirical approach, which implies an emphasis on the cognitive aspects of designing, rather than an analytical approach to the design process. It is more 
'convenient' and less 'messy' from a computational point of view. The empirical approach is supported by protocol analyses that attempt to capture the reasoning associated with design actions (see, for example, Goldschmidt, 1992). Such studies have provided insight into issues of emergence, analogy, visual reasoning, and the use of representations in design. The connection between these insights and new tools ought to help improve the fit between their affordances and design actions-between the peg and the hole.

The second paradigm, though, is more fundamental and critical to understanding where the profession of architecture is heading. In approaching computational tools as a 'horseless carriage', the observation shifts to include the practice as well as the tools and their products. The promise afforded by the new tools includes the ability to represent in the tools and the products themselves what was formerly held in practice. As such, they include an understanding of the implicit values once held exclusively by architects. And as has happened when drawing were first introduced into the practice of architecture, the organization of the work itself changes, as are the products, along with the identity of the designer and the image of practice.

The implications for Architecture are clear. In the 'square peg/round hole paradigm', observing the cognition and behavior of the designer is critical. If architects are to have better (more effective) design tools, the tool-makers need to examine the way designers reason and work. By matching affordances with design actions the tools can support, in a more inclusive manner, design reasoning can promote wisdom in their use. But they need to make the distinction between designer and design practice. While the cognitive ways in which designers work will not radically change due to their use of computational tools, the practice of design will. The 'horseless carriage' paradigm tells us that, through technology, current practices will be displaced, and new ones introduced. The question is how and how much.

\section{Acknowledgements}

The ideas in this paper owe much to discussions and previous publications in collaboration with Thomas Chastain, now a practicing architect in Berkeley, California, and to the work of my students at the University of California, Berkeley.

\section{References}

Aberdeen Group (1999) Collaborative product commerce: delivering product innovations at internet speed Market Viewpoint Vol 12 No 9 
Benne, B (2004) Techno-organizational models to support construction industry work processes, $\mathrm{PhD}$ dissertation, University of California, Berkeley

Boulding, K E (1956) The image: knowledge in life and society University of Michigan Press, Ann Arbor, MI

Canter, D (1977) The psychology of place St. Martin Press, New York Chastain, T, Kalay, Y E and Peri, C (2002) Square peg in a round hole or horseless carriage? Reflections on the use of computing in architecture $A u$ tomation in Construction Vol 11 No 2 pp 237-248

Coen, M (1998) Design principles for intelligent environments 15th National Conference on Artificial Intelligence AAAI Press pp 547-554

Gibson, J J (1977) The theory of affordances, in R Shaw and J Bransford (eds) Perceiving, acting and knowing, Lawrence Erlbaum, Hillsdale, NJ

Goldschmidt, G (1992) Criteria for design evaluation: a process-oriented paradigm in Y E Kalay (ed) Evaluating and predicting design performance, Wiley Interscience, New York pp 67-79

Halasz, I (1979) Introduction Processes in architecture: a documentation of six examples, Plan 10 MIT School of Architecture and Planning, Cambridge, MA pp 6-7

Harrison, S and Dourish, P (1996) Re-place-ing space: the roles of place and space in collaborative systems. CSCW'96 (an ACM publication).

Mozer, M C (1988) The Neural Network House: an environment that adapts to its inhabitants, in M Coen (ed) AAAI Spring Symposium on Intelligent Environments, AAAI Press, Menlo Park, CA pp 110-114

Negroponte, N (1975) Soft architecture machines MIT Press, Cambridge, MA p 102

Reich, R (1987) Entrepreneurship reconsidered: the team as hero The Harvard Business Review May-June

Virilio, P (1984) Guerre et Cinéma: Logistique de la perception Édition Cahiers du Cinéma, Paris

Womack, J P, Jones, D T and Roos, D (1991) The machine that changed the world: the story of lean production Harper Collins, New York 